\title{
As "Marcas" em Territórios Formados por Grupos Étnicos Alemães a Partir dos Estereótipos Linguagem, Trabalho e Religiosidade O Caso da Comunidade Rural de Linha Acre - Cândido Godói (RS)
}

\author{
http://dx.doi.org/10.21527/2237-6453.2020.50.89-108
}

Recebido em: 23/10/2018

Aceito em: 7/8/2019

Rejane Inês Kieling ${ }^{1}$

\begin{abstract}
RESUMO
A inserção de uma mentalidade industrial no meio rural com a produção de alimentos em escala vem se apresentando como indutora de mudanças em pequenas comunidades rurais, que se veem diante da necessidade de buscar alternativas que visem a sua continuidade em termos físicos, mas também no que se refere as suas especificidades sociais e culturais. $O$ presente estudo está pautado na identificação de aspectos relacionados aos estereótipos que "marcam" territórios formados por grupos sociais teuto-brasileiros, por se considerar que sejam relevantes para que estes atores possam encontrar novos significados no meio em que vivem. Este retorno ao passado só é possível por meio das lembranças e da memória que se faz presente no cotidiano, manifestada nas tradições, nos hábitos e nos costumes, como algo imperceptível, mas com força para modificar o futuro. A metodologia utilizada para coleta de dados deu-se com a utilização de relatos orais em pesquisa etnográfica, realizada na comunidade rural de Linha Acre - Cândido Godói (RS) durante os anos de 2016 e 2017. Durante a fase de análise dos dados foi possível constatar a presença de enraizamento no que diz respeito à presença de construções estereotipadas nos elementos linguagem, trabalho e religiosidade, escolhidos para a pesquisa.
\end{abstract}

Palavras-chave: Memória. Estereótipos. Imigrantes alemães.

THE "MARKS" ON TERRITORIES FORMED BY GERMAN ETHNIC GROUPS ON THE BASIS OF SUCH STEREOTYPES AS LANGUAGE, WORK, AND RELIGIOSITY: THE CASE OF THE LINHA ACRE RURAL COMMUNITY - CÂNDIDO GODÓI (RS)

\section{ABSTRACT}

The spread of an industrial mentality in rural areas by means of large-scale food production has been driving change in small rural communities that are compelled by necessity to look for alternatives aimed at their continuity not only in physical terms, but also with regard to their social and cultural specifities. This study is focused on identification of aspects related to stereotypes that "mark" territories formed by social groups of German Brazilians as they are considered to be relevant so that said players may find new meanings in the environment they live. This return to the past is only possible by means of recollections and memory that is present in the everyday life and reveals itself in traditions, customs, and habits as something imperceptible but powerful enough to change the future. The technique used for data collection was in-depth interviews in ethnographic research carried out in the Linha Acre rural community, Cândido Godói (RS) in 2016 and 2017. At the data analysis stage, rootedness with regard to stereotyped constructions in such elements as language, work, and religiosity chosen for the research was positively verified.

Keywords: Memory. Stereotypes. German immigrants.

\footnotetext{
${ }^{1}$ Doutora em Desenvolvimento Regional pela Universidade de Santa Cruz do Sul (Unisc). Professora da Faculdade de Tecnologia do Cooperativismo (Escoop). rejanekieling@hotmail.com
} 
A inserção de novas formas de produtividade agrícola relacionadas à modernização da agricultura vem alterando significativamente o relacionamento do homem com os recursos naturais, contribuindo para a introdução de uma mentalidade industrial no campo, cenário que vem modificando o espaço e o modo de vida das pessoas que vivem no meio rural.

Aceitando-se que processos derivados de ações do tipo "top down" sejam responsáveis por conflitos e distorções e causadores de profundas transformações no cotidiano dos indivíduos e das comunidades rurais, tem-se como premissa deste estudo a urgência de buscar alternativas que visem à autonomia dos atores, promovendo sua emancipação. O que significa afirmar que tais alternativas estejam intrinsecamente conectadas ao entendimento da construção do território a partir da base, em que as diferentes territorialidades (cultura, religião, hábitos, dialetos, saberes tracionais, comida, etc.), manifestadas por meio da memória dos indivíduos e do lugar, sejam valorizadas e consideradas em projetos de desenvolvimento rural.

A memória percebida pela sua interseção entre indivíduo/cultura permite ampliar sua propriedade estática de conservar informações, conferindo-lhe um aspecto dinâmico que possibilita pensar a sociedade no presente por meio de sua relação com o passado, decifrando o que somos hoje e o que já fomos, o que também pode ser compreendido como a construção das identidades que se traduzem pelo sentimento de pertencer a algum lugar. A memória flui livremente nas relações sociais por meio da interação permanente e inconsciente entre a realidade objetiva e subjetiva dos indivíduos.

Como recorte empírico foi escolhida a comunidade rural de Linha Acre, pertencente ao município de Cândido Godói-RS - Brasil, que faz parte da região da Grande Santa Rosa. A economia dessa comunidade depende substancialmente da produção agrícola de commodities, principalmente soja, milho e trigo, além da produção leiteira, também inserida na lógica industrial.

A escolha da comunidade rural de Linha Acre também possui caráter pessoal, uma vez que a autora desta pesquisa nasceu nessa comunidade. Mesmo tendo saído em tenra idade dessa localidade, manteve, principalmente na infância, convívio com os avós paternos e maternos, demais parentes e moradores, participando do seu cotidiano e de suas atividades culturais, conservando, inclusive, a compreensão do dialeto alemão Hunsrückisch ainda usado no lugar nos dias atuais.

O presente artigo norteia-se pela identificação de estereótipos relacionados à etnicidade dos atores e na compreensão de que tais aspectos devam ser levados em consideração em ações voltadas ao desenvolvimento de comunidades rurais, uma vez que possam ter deixado "marcas" nesse território, imprimindo, portanto, características relacionadas ao comportamento de grupos sociais como as que foram analisados na comunidade pesquisada.

\section{REVISÃO DE LITERATURA}

A reflexão proposta para este estudo conecta-se à relação entre memória e os estereótipos que fizeram e fazem parte de sua construção. Quanto daquilo que somos ou acreditamos ser é forjado por construções estereotipadas? No entendimento de Bosi (2013), existe um evidente empobrecimento das percepções dos indivíduos, seja por 
preguiça ou má vontade, o fato é que se torna mais fácil aceitar o que já foi dito do que despender esforços ao trabalho árduo da atenta observação do que está ao seu redor, contudo esse enxergar o mundo através das mediações impostas representa inquestionável perda para os indivíduos e para a sociedade.

Bosi (2013) defende que os estereótipos penetram com tal força em nossas percepções diárias como se fosse algo biológico, promovendo um imperceptível e perigoso estreitamento do campo mental, por condenar a sociedade a repetir concepções equivocadas que se alimentam justamente dessa ausência do ato de pensar por si mesmo, fomentando a perpetuidade de preconceitos e valores deturpados. Mesmo reconhecendo tratar-se de uma tarefa difícil, a autora defende a necessidade de refletir sobre as vicissitudes da opinião e estender os ângulos de visão no sentido de vencer os limites estreitos impostos pelas construções estereotipadas e empenhando esforços na luta contra o falso, o que significa passar da opinião para o conhecimento, numa relação saudável e contínua entre sujeito e objeto.

A viagem de retorno para a retomada do que ficou para trás certamente não é fácil. Exige um estado mental que realmente deseje recuperar a consciência sobre si mesmo, buscando o que Bosi (2013) denomina de caminhos familiares, que podem ser interpretados como lugares de reconhecimento da memória, que são capazes de identificar traços biográficos que reconduzam à origem ou ao Ursprung. ${ }^{2}$

Nesse sentido os lugares escolhidos na comunidade rural pesquisada percorreram os caminhos familiares relacionados à linguagem, ao trabalho e à religiosidade deste grupo social.

\section{O Hunsrückich e seu Papel na Construção de um Sentimento de Orgulho e de Pertencimento Étnico}

Com relação ao componente étnico relacionado à linguagem, os descendentes de imigrantes alemães entrevistados para esta pesquisa narraram que, para os colonos alemães que vieram para o Brasil, a barreira da língua foi um fator de preocupação ao iniciarem a vida em solo estrangeiro. A sua língua materna (alemã) destoava muito do Português, fato que pôde ser observado pela dificuldade que ainda muitos idosos têm em usar este idioma, sentindo-se mais à vontade ao se comunicarem fazendo uso do dialeto Hunsrückich.

A linguagem pode agir, portanto, tanto como fator de inclusão como de exclusão. Pupp Spinassé (2008) explana as fases relacionadas à linguística vividas por imigrantes vindos da Alemanha, desde o confronto inicial com o idioma dos brasileiros, sua adaptação e as modificações que a língua materna alemã foi sofrendo ao longo desses quase dois séculos, desde o início da colonização alemã no Rio Grande do Sul.

A primeira fase caracteriza-se pela formação de espaços isolados em que as comunidades se fortaleciam com o uso da língua materna alemã, mesmo com variantes linguísticas, pois nas suas regiões de origem na Alemanha havia diferenças de lingua-

\footnotetext{
${ }^{2}$ Nunes (2014), ao debruçar-se sobre a obra de Walter Benjamin, explica que o que ele denomina de Ursprung (salto às origens) vincula-se a uma visão de ruptura à concepção linear e homogênea apresentada pela história universalmente aceita. O Ursprung não significa um simples retorno ao passado, mas uma possibilidade de modificá-lo e, assim, converte-se também num espaço que se abre para o futuro.
} 
gem com o uso de dialetos peculiares a cada local. Com o passar do tempo foi se desenvolvendo um dialeto próprio nas colônias alemãs estabelecidas no Rio Grande do Sul, com elementos linguísticos mais próximos ao falado na região do Hunsrück, de onde veio a maioria dos imigrantes pobres da Alemanha. Tornquist (1997) descreve esse fenômeno como uma "ilha linguística", formada para assegurar a sobrevivência desses grupos sociais em terra estrangeira e ajuda a compreender o uso desse dialeto ainda nos dias atuais.

Mesmo falando dialetos diferentes, dependendo da sua região de origem, os membros de tal grupo étnico/linguístico minoritário se mantêm unidos por causa do sistema de valores em comum. $O$ funcionamento para o desenvolvimento e a estabilidade de tais sistemas de valores e normas é a interação entre os membros do grupo durante um período prolongado, resultando em densas redes sociais de comunicação (TORNQUIST, 1997, p. 160).

Devido à precariedade em termos de políticas governamentais de apoio aos imigrantes, eles tiveram de organizar as comunidades em que viviam construindo igrejas e escolas, além de ser de sua responsabilidade a contratação dos professores e a manutenção das escolas, fato que justifica o uso do idioma alemão no ensino aos filhos dos colonos. Além disso, também "os cultos religiosos nas comunidades eram em alemão, já que o pastor era um dos alemães e sua língua a mesma da comunidade. Eles praticamente não precisavam sair da colônia, pois tinham lá tudo o que precisavam para a vida dentro dessa ilha linguística" (PUPP SPINASSÉ, 2008, p. 5).

A segunda fase relativa ao processo de transformações na linguagem se dá com a chegada de outros grupos de imigrantes, em especial os italianos, mas também com a presença dos próprios brasileiros, e no caso da comunidade de Linha Acre, também deve-se mencionar a presença da etnia polonesa. Esse fato foi alterando paulatinamente a fisionomia das colônias. A vizinhança já não era formada somente por indivíduos da mesma origem étnica. Isso, somado à necessidade de comerciar com pessoas de diferentes grupos étnicos, foi cada vez mais exacerbando a necessidade de falar o idioma Português. Conforme Pupp Spinassé (2008, p. 6),

nessa nova fase, contudo, a língua nacional se aproxima mais, começa a se tornar algo palpável e, assim, elemento indispensável para o comércio, as negociações e para a inserção no quadro social como cidadão ativo politicamente. Com isso, ela também se tornou, muitas vezes, um problema. Os "teuto-brasileiros" não conseguiam se integrar tão facilmente com os vizinhos. A partir de então se inicia uma tentativa maior de aprender o Português. Nesse momento, certamente surgiram muitos questionamentos em relação à própria identidade: por que falavam alemão, se não eram alemães. Especula-se que problemas de identidade e confrontos de gerações devam ter ocorrido, pois na opinião dos pais, a língua, que graças ao isolamento tinha sido mantida como um fator identitário, era a responsável por manter uma ligação com a pátria abandonada. No entanto, para a juventude, essa "nostalgia" não fazia muito sentido. Eles já tinham uma pátria, no caso, o Brasil.

É interessante atentar para o fato de que os nascidos no Brasil e seus descendentes já não guardavam mais o sentimento de pertencer ao país de origem de seus antepassados. Essa realidade colocava em risco o Deutschtum (expressão que representa a 
identidade étnica dos imigrantes alemães). Seyferth (2004) apresenta algumas relevantes questões que servem para demonstrar a tentativa de manter tal identidade étnica. Conforme a autora, o Deutschtum era mantido,

através da atuação de associações, como sociedades de tiro, ginástica, canto, culturais (que incluíam grupos de teatro, pequenas bandas e orquestras, etc.) e agrícolas. $O$ objetivo expresso nas publicações escritas dessas associações era transmitir à população de origem alemã a cultura, a língua e o espírito esportivo e associativo dos alemães (p. 64).

A autora supramencionada enaltece o papel desempenhado pela imprensa, que conseguiu, com a utilização de um conjunto de publicações em língua alemã no Brasil, como jornais, almanaques, folhetos, livros de memórias e romances, além de outros escritos, popularizar uma espécie de literatura teuto-brasileira.

A preservação da etnicidade alemã por meio do uso do dialeto alemão em colônias formadas por teuto-brasileiros sofreu significativo abalo com a nacionalização imposta pelo governo Vargas no período do Estado Novo (1937/1945). A política de nacionalização estava fundamentada na concepção de segurança nacional, em que qualquer influência ideológica estrangeira era vista como uma ameaça à ordem estabelecida, fazendo-se necessário incutir o sentimento de amor à pátria brasileira nas populações de origem europeia.

Por meio do Decreto Federal no 406, datado de 4 de maio de 1938, foram extintas as escolas estrangeiras, que, conforme mencionado anteriormente, haviam sido construídas e mantidas pelos imigrantes europeus devido ao descaso do governo brasileiro. A seguir apresenta-se os artigos relacionados às principais mudanças no cotidiano das comunidades de descendentes de imigrantes europeus:

Art. 85. Em todas as escolas rurais do país, o ensino de qualquer matéria será ministrado em português, sem prejuízo do eventual emprego do método direto no ensino das línguas vivas. $\S 1$ 을 As escolas a que se refere este artigo serão sempre regidas por brasileiros natos. $\S 2$ ㅇ Nelas não se ensinará idioma estrangeiro a menores de quatorze (14) anos. § 3 o Os livros destinados ao ensino primário serão exclusivamente escritos em língua portuguesa. $§ 40$ Nos programas do curso primário e secundário é obrigatório o ensino da história e da geografia do Brasil. § 5 o Nas escolas para estrangeiros adultos serão ensinadas noções sobre as instituições políticas do país. Art. 86. Nas zonas rurais do país não será permitida a publicação de livros, revistas ou jornais em línguas estrangeiras, sem permissão do Conselho de Imigração e Colonização. Art. 87. A publicação de quaisquer livros, folhetos, revistas, jornais e boletins em língua estrangeira fica sujeita à autorização e registro prévio no Ministério da Justiça (BRASIL, 1938).

Esse processo não se deu, contudo, de forma pacífica. Muito pelo contrário, foi um período gerador de traumas, os quais ainda se fazem presentes em conversas, principalmente com pessoas mais idosas, que vivenciaram, de forma direta ou indireta, repressões manifestadas das mais diversas formas, tais como: prisões, torturas, queima de livros, apreensão de rádios, entre outras. A vida diária foi afetada de forma drástica, pois muitos moradores simplesmente não sabiam falar nada em Português. E o simples fato de serem surpreendidos falando em uma língua estrangeira era motivo para serem presos (KREUTZ, 1991). 
Esse fato foi possível constatar na fala de uma das entrevistadas idosas, que lembra que

foi um tempo muito difícil. Meu pai sempre falava que ele não sabia falar em português e se fosse pego falando em alemão podia ser preso. E ainda tinham alguns vizinhos que denunciam os próprios vizinhos. Ele teve de esconder todos os documentos e livros que os pais dele tinham trazido da Alemanha, escondeu embaixo dos cochos das vacas, mas muita coisa se perdeu, e também por isso nós não temos quase nada daquilo que os antigos trouxeram da Alemanha (IDOSA 5-GRUPO 3). ${ }^{3}$

Desse processo de proibição da língua alemã deriva-se um novo fenômeno linguístico, caracterizado pela conjunção de fatores como medo e vergonha de falar alemão, necessidade de integração com os centros urbanos mais próximos, entre outros. Nessa fase, que Pupp Spinassé (2008) classifica como o 3 sistema linguístico, o Hunsrückich é considerado um marco de integração entre os idiomas Português e Alemão, ao mesmo tempo que mantém elementos que caracterizam a identidade étnica dessas populações.

O fenômeno ao qual a autora se refere é facilmente observado em localidades com descendência teuto-brasileira. Trata-se do uso de uma linguagem com palavras que apresentam forma híbrida, ou seja, "lexema português + sufixo ou prefixo alemão" ou "lexema português + forma flexional do alemão", além do uso de palavras "emprestadas" da língua portuguesa às quais foram simplesmente imprimindo um tom do alemão (PUPP SPINASSÉ, 2008, p. 10). A título de ilustração, são apresentadas a seguir algumas palavras originadas da língua portuguesa, mas que foram incorporadas e transformadas pelo Hunsrückich:

Quadro 1 - Palavras misturadas entre Português e Alemão

\begin{tabular}{|lll|}
\hline Português & Alemão & Hunsrückich \\
\hline Grama & Grass & Kramma \\
\hline Barriga (Pança) & Bauch & Panz \\
\hline Bergamota & Mandarine & Pegamot \\
\hline Caneca & Becher & Canega \\
\hline Misturar & Umrühren & Misturieren \\
\hline Chega & Es reicht & Es Chegt \\
\hline Caboclo & Mischling & Cabocler \\
\hline
\end{tabular}

Fonte: Adaptado pela autora a partir de PUPP SPINASSÉ (2008).

\footnotetext{
${ }^{3}$ Como o artigo faz parte da pesquisa de tese de Doutorado da autora, já são feitos na seção de revisão de literatura alguns cruzamentos com as falas dos entrevistados. A nomenclatura utilizada para a apresentação dos relatos orais é: IDOSO(A) - Grupos 1, 2 e 3 - divididos conforme classificação do Instituto de Pesquisa Econômica Aplicada (Ipea) - Grupo 1: idosos jovens, pessoas que têm entre 60 e 70 anos de idade; Grupo 2: medianamente idosos, pessoas a partir de 70 até 80 anos de idade, e Grupo 3: muito idosos acima de 80 anos; TRADICIONAL (agricultores que se dedicam exclusivamente à produção de grãos e leite) e TRADICIONAL/ORGÂNICO (agricultores que se dedicam à produção de grãos e leite, mas fazem parte do grupo de orgânicos).
} 
Além das palavras misturadas entre português e alemão, é interessante também apresentar um exemplo de "mistura" que os teuto-brasileiros foram construindo ao longo do tempo, em frases mais longas, como: "De Man hat de mula mit de rehle dorich de banhado in das potrea getockt", que em alemão seria "Der Mann hat den Esel mit der Peitsche durch den Sumpf die Weide getrieben", o que, em português, pode ser traduzido para "O homem tocou a mula com o relho através do banhado para o potreiro"(PUPP SPINASSÉ, 2008, p. 11).

Nas falas dos entrevistados também foi possível constatar situações que demonstram essa mistura de linguagem, como no exemplo da Idosa 3, Grupo 3, mesmo tratando-se de uma pessoa que possui maior espontaneidade no uso do dialeto alemão, utiliza-se de palavras em Português junto com esse dialeto: "Die Wowo hot sich Schneider geschrieb. Unn de Dilvo unn de Schneider unn die Wowo, die woore vizinhos in Deitschland". ${ }^{4}$

A partir desses exemplos pode-se perceber no Hunsrückich seu papel integrador. Ao mesmo tempo que mantém elementos da língua de origem dos antepassados que vieram da Alemanha, mostrou-se flexível às interferências comuns que todos os idiomas sofrem, devido a questões externas, como as que foram apresentadas anteriormente, mas também pela própria compreensão de que a língua é, antes de mais nada, uma representação da evolução das relações sociais. Por isso, adapta-se continuamente à necessidade de estabelecer contatos entre os indivíduos.

Além das questões mencionadas anteriormente, deve-se levar em consideração que a identidade dos atores também é composta por elementos triviais que se manifestam no cotidiano, associados ao enraizamento de um modo de vida que, assim como a religião, guarda indícios da manutenção da Kultur ${ }^{5}$ alemã. Esses indícios podem ser interpretados como construções estereotipadas explicadas por Bosi (2013) como algo que penetra no cotidiano dos indivíduos de forma imperceptível, e justamente por isso, ou seja, pelo fato de não se darem conta disso, vão sendo transmitidos entre as gerações.

\section{A Valorização do Trabalho em Comunidades Formadas por Descendentes de Imigrantes Alemães}

O segundo elemento escolhido para refletir sobre a formação da identidade dos grupos de teuto-brasileiros diz respeito à representação do trabalho na ideologia étnica desses grupos sociais, que ainda se faz presente em comunidades formadas por descendentes de imigrantes alemães, como é o caso da comunidade rural de Linha Acre.

Conforme já referido, com o passar do tempo a língua alemã foi sofrendo modificações devido, principalmente, à necessidade de adaptação ao idioma Português. Com relação ao componente ideológico vinculado ao trabalho, ao contrário, observa-se

\footnotetext{
${ }^{4}$ Tradução do dialeto Hunsrückich para português: A vovó tinha o sobrenome Schneider, o vovô Dill e o Schneider e a vovó eram vizinhos na Alemanha.

${ }^{5}$ Conforme Elias (1990, p. 25): o conceito alemão de Kultur dá ênfase especial a diferenças nacionais e à identidade particular de grupos. Principalmente em virtude disto, o conceito adquiriu em campos como a pesquisa etnológica e antropológica uma significação muito além da área linguística alemã e da situação em que se originou o conceito. [...] Enquanto o conceito de civilização inclui a função de dar expressão a uma tendência continuamente expansionista de grupos colonizadores, o conceito de Kultur reflete a consciência de si mesma de uma nação que teve de buscar e constituir incessante e novamente suas fronteiras, tanto no sentido político como espiritual, e repetidas vezes perguntar a si mesma: "Qual é, realmente, nossa identidade?"
} 
maior valorização. Para compreender essa ideia, faz-se necessário recuperar a significação sociológica implícita no termo Deutschbrasilianertum. Seyferth $(1982$, p. 2) explica que essa expressão pode ser traduzida como "pensamento nacional ou étnico-brasileiro" e "exprime as tendências positivas de identidade e inclusão num grupo étnico, considerado por seus membros como racialmente superior aos demais".

O Deutschbrasilianertum, conforme Seyferth, seria derivado da ideologia incorporada no termo germanidade, que, segundo a autora:

tem uma premissa básica: o povo alemão não precisa estar ligado a um território específico, ou a um Estado para constituir uma nação. O povo - isto é, a nação - existe na medida em que possa ser constatada uma solidariedade prescrita na idéia da Volksgemeinschaft (comunidade étnica ou nacional). Deutschtum, então é o indicador de uma condição étnica. Traz em si a idéia de que nacionalidade (ou a etnia) é herdada. Isto significa que, para ser alemão, não é preciso nascer na Alemanha. Etnia e nacionalidade são recebidas como herança ancestral e perpetuadas pelo uso do idioma alemão, pelo espírito do povo alemão e por outros critérios da mesma natureza, especificados na concepção de uma kultur alemã e uma tradição popular germânica (SEYFERTH, 1982, p. 3).

A partir do que foi apresentado na citação anterior, fica mais fácil assimilar o valor simbólico do trabalho para os descendentes de alemães. A herança cultural valorizada e mantida pelos imigrantes e pelas gerações que os sucederam, somada ao cuidado com a preservação desses valores com uma certa homogeneização - por exemplo, evitar casamentos com grupos étnicos considerados inferiores - são fatores que contribuíram para a formação de um sentimento de Heimat ${ }^{6}$ no sul do Brasil.

O elemento trabalho é considerado diferenciador em relação a outros grupos sociais, em especial os nativos do Brasil, aos quais eram atribuídas estereotipias de cunho pejorativo, em que o brasileiro era visto como preguiçoso, indolente e atrasado, reforçando inclinações literárias e de representantes da elite brasileira que defendiam a superioridade racial e cultural dos descendentes de alemães no que diz respeito a sua capacidade de empreender esforços para melhorar sua condição de vida por meio do trabalho. Conforme Seyferth (1982, p. 33),

a idéia de uma superioridade étnica (evidenciada pela "capacidade de trabalho") nivela todos os membros do grupo étnico teuto-brasileiro, já que a etnicidade, na prática, é o produto do trabalho de cada indivíduo, independente da classe social a que pertence. A língua alemã não deve ser o principal critério de identificação étnica - como era no passado [...]. A origem alemã e a consequente superioridade do "trabalho alemão" (e, sob muitos aspectos, também o uso cotidiano da língua alemã) são definidores da etinicidade teuto-brasileira.

\footnotetext{
${ }^{6}$ Heimat é uma palavra que possui um significado abstrato, portanto não pode ser traduzida simplesmente, deve ser compreendida dentro do contexto em que os imigrantes alemães se encontravam em terra estrangeira. Theis (2012, p. 3) apresenta a seguinte definição para Heimat: "é, provavelmente, o desejo de um lugar que é como um sonho, mas não pode ser alcançado porque o sonhador está em outro lugar. Esta pessoa se mudou, foi para outra cidade, outra região, outro país, ou até mesmo outro continente. Talvez a mudança para outra cidade não seja um passo tão grande, pois algumas coisas nunca mudam; algumas coisas podem ser encontradas em qualquer lugar, e assim elas dão o sentimento de Heimat à pessoa [...]". Sobre esta palavra também foi interessante observar durante as conversas, principalmente com pessoas acima de 70 anos de idade, que existe um sentimento de "saudade" da Alemanha, mesmo sem jamais terem conhecido esse país - "saudade" de algo que parece lhes ter pertencido.
} 
Uma questão adicional que deve ser considerada, tendo em vista que ajuda a compreender a adaptabilidade dos grupos descendentes de alemães da região Noroeste do Estado do Rio Grande do Sul às mudanças decorrentes da inserção das novas formas de produção apresentadas na seção anterior, está relacionada ao interesse individual dos imigrantes europeus em relação ao quesito aquisição material.

Este, conforme Salles (1986), foi um dos fatores diferenciadores dessa mão de obra no seu processo de entrada no Brasil, uma vez que possibilitava a conjunção dos interesses dos imigrantes (de enriquecimento) com os interesses dos fazendeiros que desejavam a ampliação do capital investido nas lavouras.

O trabalhador europeu, que já havia sofrido no seu país de origem o processo de perda dos seus meios de trabalho, nas condições históricas determinadas pela acumulação primitiva do capital e pelo desenvolvimento do capitalismo, passaria a viver aqui as condições de proletarização da sua força de trabalho. A perda do vínculo com seu passado histórico permitiu que ele construísse, sob novas condições de vida, ambições de "fortuna" que não lhe eram mais permitidas alimentar no seu país (SALLES, 1986, p. 87).

A mesma autora explica ainda que essa nova configuração em termos de divisão do trabalho, que não se restringe mais ao âmbito nacional, permite que haja o desenvolvimento da produção sob o domínio do capital, em consonância com a economia capitalista mundial, o que significa a subordinação dos interesses da nação ao capital. É nesse contexto que o trabalho do imigrante europeu adquire conotação de superioridade em relação a outros tipos de mão de obra, como a dos escravos, por estar em sintonia com os anseios dos mercados regrados pela égide da expansão capitalista (SALLES, 1986).

\section{A Imposição do Deutschtum por Meio do Domínio da Igreja}

O último elemento que contribui para o entendimento das "marcas" deixadas pelos teuto-brasileiros no território está relacionado à religiosidade desses grupos sociais. Estudo realizado por Werle (2014), a respeito da formação da Colônia Porto Novo, situada no extremo oeste do Estado de Santa Catarina, contribui à presente reflexão para compreender como se deu a construção de homogeneidades que repercutem na identidade da comunidade de Linha Acre.

Conforme esse autor, as primeiras colônias formadas por imigrantes alemães começaram a perceber, a partir da década de 20 , certa dificuldade em continuar produzindo nessas localidades, devido, principalmente, ao esgotamento do solo e ao fator demográfico, decorrente da entrada de novas ondas de imigração. Essa situação serviu como incentivo para que esses indivíduos procurassem outras regiões para se estabelecerem e dar continuidade ao seu modo de vida tradicional. Werle (2014) explica que essa migração interna foi promovida por inúmeras empresas colonizadoras privadas e associações comprometidas com os aspectos ligados ao fortalecimento da religião entre esses imigrantes. As Colônias Novas (como eram denominadas para se diferenciarem das que foram colonizadas no século 19) foram organizadas pela associação Volksverein für die deutschen im Rio Grande do Sul, que, segundo o autor, 
trata-se da Sociedade União Popular para Alemães Católicos no Rio Grande do Sul, fundada em 1912 e idealizada pelos jesuítas alemães de São Leopoldo, R.S. Esta particularidade, se analisada mais detalhadamente, indica que a formação da colônia envolve um conjunto de significados que ultrapassa a simples venda de terras, cuja compreensão requer a análise da atuação da Volksverein (como era chamada a Sociedade União Popular entre os colonos), bem como os pensamentos sociais e os objetivos dos religiosos que a orientavam (WERLE, 2014, p. 18).

As premissas dessa associação eram de preservação da religiosidade entre esses colonos, que não deveriam misturar-se com outros grupos étnicos para manter o que eles denominavam de "espírito comunitário". Etnia e religiosidade caminhavam juntas, a fim de manter valores intrínsecos que garantissem a manutenção do Deutschbrasilianertum e promovendo, portanto, "sociedades homogêneas, nas quais não há mistura de nacionalidades nem de religiões. Somente nestas sociedades é que seria possível a vida comunitária e harmônica" (WERLE, 2014, p. 23).

É nesse campo de investigação que se compreende a necessidade de se ater a uma revisão dos conceitos relacionados à memória cultural, campo de pesquisa que tem no legado do pensamento do filósofo alemão Friedrich Nietzsche sua principal base de sustentação.

Refletindo sobre a origem dos preceitos morais estabelecidos e aceitos socialmente, Nietzsche (2009) questiona sobre as condições históricas existentes que permitiram tais construções.

Sob que condições o homem inventou para si os juízos de valor "bom" e "mau"? E que valor têm eles? Obstruíram ou promoveram até agora o crescimento do homem? Ou, ao contrário, revela-se neles a plenitude, a força, a vontade de vida, sua coragem, sua certeza, seu futuro? (p. 83).

O instigante e provocativo questionamento feito pelo autor relaciona-se às possíveis razões que permitiram ao homem tornar-se "um animal capaz de fazer promessas reduzindo-o a conviver com as regras impostas pelo seu meio social, a partir de padrões morais preestabelecidos, a tornar-se igual entre iguais" (SILVA, 2012, p. 10). No momento em que o homem faz promessas, ele aceita as regras impostas para que seja possível conviver em sociedade, sujeita-se às normas e valores previamente estabelecidos e suas atitudes tornam-se previsíveis, o que também pode ser interpretado como um elemento gerador de confiança entre os grupos sociais. Conforme o mesmo autor, o processo constitutivo dessa memória não se deu, contudo, de forma espontânea. Ele explica que o pensamento nietzschiano associa seu surgimento a sacrifícios e até mesmo a violências: "Esse homem de memória previsível, constante e necessário aprendeu, através de uma longa trajetória, a tornar-se útil e necessário, depois de ter padecido todo um processo de violenta domesticação para poder prometer" (SILVA, 2012, p. 11).

A construção de uma memória previsível está associada a instrumentos de controle, em que os instintos humanos tiveram de ser contidos para que o indivíduo pudesse ser reconhecido como bom diante dos critérios de moralidade socialmente determinados, assumindo um comportamento que o autor denomina de instinto de rebanho. ${ }^{7}$

Para ver em (NIETZSCHE, 2001, p. 123). 
Esse instinto de rebanho, que os indivíduos foram constrangidos a aceitar, denota a existência de um processo de construção mnemônica com subtração das liberdades individuais, indicando que as tradições e os costumes possam ter sido criados a partir do que Nietzsche (2009) denomina de camisa-de-força social.

Conforme Silva (2012), o pensamento nietzschiano interpreta essas formas de castigo como práticas que vão além da transformação do homem em um ser domesticado. O castigo ou a penalidade teria servido como uma forma de enquadramento social e satisfação de um desejo de crueldade inerente aos instintos primitivos do homem. A memória imposta pela dor e pelo sofrimento teria servido como instrumento regulador da sociedade, uma vez que, ao inibir o esquecimento, conecta a ação dos indivíduos aos valores morais estabelecidos.

\section{PROCEDIMENTOS METODOLÓGICOS}

No que diz respeito aos procedimentos metodológicos foi utilizada a história de vida como principal técnica de coleta de dados, abordagem qualitativa em pesquisa etnográfica.

Partindo da necessidade de maior familiaridade com a localidade estudada, iniciou-se, em 2014, observação junto a comunidade de Linha Acre, com o objetivo de ir desvelando o fenômeno, à medida que a pesquisadora fosse captando, por intermédio da sua sensibilidade, mundos interiores que começam a tornar-se externos com o convívio e a confiança dos entrevistados e outros moradores da localidade, e fossem aos poucos se conectando com a proposta de estudo e pudessem, dessa forma, sentirem-se estimulados a conversar sobre suas lembranças e percepções a respeito do fenômeno vinculado ao objetivo central da pesquisa.

A continuidade da coleta de dados deu-se nos anos de 2016 e 2017 por meio de relatos orais, em que foi utilizada a história oral, justamente por reconhecer-se que a memória não está em algum lugar do passado, mas faz parte do presente, pois o comportamento dos indivíduos está sempre sendo influenciado pela transferência dos saberes dos antepassados, conforme enfatizado por Minayo (2016, p. 12): "as sociedades vivem o presente marcado pelo passado e é com tais determinações que constroem seu futuro, uma dialética constante entre o que está dado e o que será fruto de seu protagonismo". Bosi (1983) contribui com a afirmativa de que a história oral junto com a valorização da memória ganhou espaço no campo das Ciências Humanas, como metodologia de pesquisa.

Ainda sobre os procedimentos metodológicos usados para a realização da pesquisa, cabe mencionar que, devido à necessidade de maior convívio com os atores da pesquisa, por ser necessário compreender e assimilar suas percepções sobre o fenômeno, julgou-se adequado utilizar a pesquisa etnográfica como suporte às técnicas utilizadas, uma vez que tal pesquisa, segundo Severino (2007), visa a compreender os processos na sua cotidianidade.

Há de se salientar, entretanto, que o convívio foi facilitado pela familiaridade da autora deste artigo com a comunidade na qual nasceu e mantém vínculos, fato que certamente permitiu aos entrevistados externar com maior liberdade suas lembranças e percepções. Além disso, também se deve mencionar que a autora se fez acompanhar por 
sua mãe nas conversas com os idosos, os quais se sentiram mais à vontade na presença de alguém que também faz parte de suas memórias e pela compreensão do dialeto Hunsrückisch, o que deu maior fluidez ao processo de reconstrução de suas memórias.

\section{ESTERIÓTIPOS ANALISADOS NA COMUNIDADE RURAL DE LINHA ACRE: Linguagem, Trabalho e Religiosidade}

Durante as conversas com os moradores de Linha Acre, foi possível constatar que, mesmo que a comunidade tenha passado e ainda esteja passando por mudanças, persiste um sentimento de orgulho relacionado às características de sua origem étnica teuto-brasileira, as quais são prevalecentes na comunidade. Isso pôde ser percebido nos significados vinculados ao uso do dialeto alemão entre os moradores descendentes de imigrantes dessa etnia. Além da linguagem também demonstraram valorizar atributos relacionados ao trabalho como um diferencial em relação a outros grupos étnicos.

Da mesma forma como a religião, o uso da linguagem exerceu importante papel no processo que visava à manutenção do Deutschtum em comunidades rurais como a Linha Acre. Conforme mencionado anteriormente, a língua materna dos imigrantes alemães foi sofrendo modificações ao longo do tempo, o que é compreensível devido às necessidades que esses grupos tiveram para se comunicar utilizando o idioma Português. Como exemplo, os entrevistados idosos lembraram da dificuldade em se comunicarem em Português para comercializar produtos como a banha de porco no mercado.

O uso do idioma Português nas relações de comércio também esclarece porque os homens mais idosos têm maior facilidade para se comunicar nesse idioma, ao passo que as mulheres idosas praticamente usaram somente o dialeto Hunsrükich durante as entrevistas, pois, como eram eles que assumiam o papel de comerciar, foram forçados a aprender o idioma Português. Em geral, no entanto, o que se observou nas conversas foi um verdadeiro hibridismo linguístico, com frases que usam formas misturadas entre o Português e o Alemão, mas perfeitamente compreendidas entre os moradores.

Em conjunto com a facilidade de se comunicarem usando o dialeto alemão, mesmo entre os jovens, que falavam mais em Português, mas conseguiam compreender os diálogos com uso do dialeto alemão sem nenhuma dificuldade, os entrevistados manifestaram sentirem-se alemães. Tal sentimento pôde ser percebido, num primeiro momento, ao mencionarem que a utilização do dialeto alemão (com exceção dos mais jovens) é considerado mais espontâneo nas conversas entre os vizinhos, parentes e amigos. Na sequência das conversas também foram relatadas situações visualizadas por meio de lembranças que revelaram elos com o passado, como nos momentos em que são entoados cantos em alemão para compor celebrações religiosas das quais participam na comunidade ou em outras localidades próximas.

Sempre quando rezam ou cantam em alemão na igreja eu sinto uma emoção muito forte, volta na mente imagens de quando eu era criança e ia na missa com o pai, a mãe e meus irmãos. Eu não sei explicar, mas parece que no alemão tudo faz mais 
sentido, porque tudo que eu aprendi, o jeito de ser e a educação que eu recebi dos meus pais, tudo sempre foi ensinado em alemão e eu devo isso a eles. Por isso o alemão é mais forte do que o brasileiro ${ }^{8}$ (TRADICIONAL/ORGÂNICO 2).

Importante ressaltar que o uso do idioma Alemão em pequenas comunidades formadas por imigrantes, como é o caso da comunidade pesquisada, levou ao que Pupp Spinassé $(2008$, p. 5) classifica como a formação de uma "ilha linguística". Cenário que foi responsável pelo isolamento dessas comunidades, pois, ao mesmo tempo que adquiriram dinâmica própria, foram conduzindo suas vidas afastadas de outras culturas, fato que ajuda a compreender o sentimento de medo que os mais idosos relataram com relação ao desconhecido, principalmente no que se refere ao grupo étnico afro-brasileiro, com o qual, segundo os entrevistados, os pais recomendavam que tivessem especial cuidado, pois no entendimento deles eram pessoas que representavam perigo. Com o objetivo de ilustrar esse sentimento dos moradores em relação ao outro, foram escolhidos dois depoimentos.

O primeiro foi narrado pelo entrevistado Tradicional/Orgânico 2. É a história de Noé Ferreira, falecido em 1990 na Linha Acre. Noé, como era conhecido, teria sido um andarilho vindo de São Nicolau-RS, sem família e sem bens materiais. Quando chegou na Linha Acre, ainda jovem, por ser negro, despertou medo nas pessoas, porque, conforme o entrevistado:

Quem não era alemão era um intruso. Mas logo o Noé começou a trabalhar em algumas casas, onde também passava as noites. Com o passar do tempo tornou-se uma pessoa querida por todos, especialmente pelas crianças, porque ele não chegava nunca sem um doce para oferecer para elas. Pena que ele tinha o vício da bebida e foi por isso que ele morreu. Ele sofreu um acidente num dia que tinha tomado álcool puro. Como ele não tinha família, a comunidade fez um mutirão e comprou um túmulo e fizeram uma lápide, por causa que ele era daqui, sabe?

E o segundo exemplo foi coletado ouvindo uma conversa entre um casal que mora no centro da cidade, mas que serve para demonstrar como os estereótipos relacionados ao uso da língua alemã ainda se fazem presentes nos dias atuais. $O$ episódio aconteceu da seguinte forma: durante uma conversa, a esposa contou que havia permitido que um vendedor, de origem étnica negra, entrasse na residência para mostrar os produtos que desejava vender. O marido advertiu-a de que não devia tê-lo deixado entrar, pois poderia tratar-se de um bandido. Ela mais que depressa defendeu-se alegando que, "mesmo sendo negro", o vendedor falava em alemão, por ter sido criado por uma família de alemães, "gutes deutcheleute" (boas pessoas alemãs). O argumento de confiança atribuído por ela foi de que esse vendedor era "so wie uns" (assim como nós).

As duas situações mencionadas demonstram que a cor da pele remete a estereotipias que se vinculam à forma como os teuto-brasileiros vêm atribuindo significados pejorativos a grupos sociais que consideram diferentes e até inferiores por não terem recebido a cultura alemã, sendo mais exacerbado tal sentimento em relação aos nativos do Brasil, devido às construções que enaltecem atributos negativos a esses grupos sociais. É a partir de exemplos como os anteriormente mencionados que é possível fa-

8 A palavra "brasileiro" é usada pelo entrevistado como sinônimo de idioma Português. 
zer uma ligação com o entendimento de Woodward (2014) a respeito da relação entre identidade e diferença. Para essa autora, a identidade depende da diferença, ou seja, é explicada por estruturas que classificam grupos com base em determinadas características, como no caso, os que foram educados na cultura alemã e os que não foram. Conforme a autora,

a identidade, pois, não é o oposto da diferença: a identidade depende da diferença. Nas relações sociais, essas formas de diferença - a simbólica e a social - são estabelecidas, ao menos em parte, por meio de sistemas classificatórios. Um sistema classificatório aplica um princípio de diferença a uma população de uma forma tal que seja capaz de dividi-la (e a todas a suas características) em ao menos dois grupos opostos - nós/eles [...] (WOODWARD, 2014, p. 40).

Concomitantemente ao que já foi apresentado sobre o uso da linguagem, pode-se observar que, para os atores analisados, indivíduos que "falam em alemão" são considerados mais trabalhadores. De acordo com Seyferth (1982, p. 33), os estereótipos ligados à "capacidade de trabalho", relacionados aos grupos étnicos alemães, teriam sido forjados a partir de comparações pejorativas, principalmente com o brasileiro, ao qual eram atribuídas características que denotavam certa aversão ao trabalho, ao mesmo tempo que enalteciam a valorização do trabalho empreendido pelos alemães e seus descendentes, vistos como etnicamente superiores. A mesma autora explica ainda que essa construção ideológica de superioridade do trabalho dos descendentes de imigrantes alemães em relação a outros grupos étnicos se deu, em grande parte, devido à aceitação de que essa capacidade de trabalho é herdada, ou seja, transferida entre as gerações, o que ajuda na compreensão de que persistam nos dias atuais comportamentos preconceituosos e racistas em comunidades formadas por esses grupos étnicos.

Durante as entrevistas o elemento trabalho foi percebido como algo que exerce significativa influência na percepção de atributos relacionados à forma como estes indivíduos se identificam. $\mathrm{O}$ que foi possível concluir pela maneira como fizeram referência à rotina diária de levantarem cedo e dedicarem grande parte das horas do dia ao trabalho, enaltecendo repetidamente o fato de não terem horário para terminar o serviço em períodos de plantio e de colheita. Conforme descrito pela entrevistada Tradicional 4, "agora com as máquinas, quando nós vamos semear a gente não tem horário. Tu vai de manhã cedo e muitas vezes passa do horário do meio-dia e se não tá pronto vai noite adentro e pra colher é a mesma coisa".

Alguns depoentes explicaram que esse "gosto" pelo trabalho teria se originado na infância, pois tiveram de ajudar nas atividades da propriedade desde crianças: "Com seis, sete anos eu já tinha que cuidar dos pintinhos e dar água pro porquinho" (TRADICIONAL/ORGÂNICO 1). Além de terem, em geral, começado a trabalhar com pouca idade, foi mencionado um fato curioso relacionado à infância: ao fazerem menção aos incentivos que eram gerados pelos adultos para que as crianças se sentissem obrigadas a trabalhar, eles contaram que no período do ano que antecedia o Natal, os pais 
"ameaçavam" as crianças que não fizessem os serviços que lhes eram solicitados, como a limpeza do pátio, com a figura do Pelznickel, ${ }^{9}$ que era uma espécie de contraditório do Cristkindchen (o menino Jesus).

Eles contam, ainda, que seus pais diziam que o Pelznickel viria para castigar as crianças que desobedecessem, e até mesmo simulavam situações em que alguém entre os adultos vestia uma fantasia como se fosse esse personagem e aparecia arrastando correntes para assustar as crianças. E assim também faziam com a figura do Cristkindchen, em que alguém usando roupas brancas aparecia para que as crianças acreditassem que, se fizessem todo o trabalho solicitado, seriam por ele recompensadas.

Não foi mencionado nenhuma vez que se consideram superiores a outros grupos étnicos no quesito trabalho, até mesmo foi enaltecido que os poloneses seriam mais trabalhadores, o que não significa, contudo, que não enxerguem o trabalho como um diferencial dos grupos teuto-brasileiros.

Em conversas mais descontraídas (fora do ambiente das entrevistas) foi possível captar falas que exprimem a existência de estereotipias que denotam uma "devoção" ao trabalho por parte desses atores, conforme ilustrado em frases como: "colono não tira férias", relacionando ao fato de terem trabalho de domingo a domingo com o gado leiteiro. Por isso, mesmo que participem de alguma atividade festiva, devem retornar cedo para fazer esse serviço e não podem ausentar-se nunca para gozo de férias; "eu mesma faço o serviço de casa", frase que traz um sentido implícito de que contratar alguém para realizar o serviço doméstico seria algo de gente preguiçosa, nesse caso a mulher, a qual, no entendimento deles, deve assumir o trabalho da casa e ainda ajudar nas atividades da propriedade rural; "quem trabalha na roça não tem como ter as unhas arrumadas, isso é coisa de gente da cidade". Nessa frase foi possível perceber um certo orgulho na aparência que transparece ser alguém que trabalhe mais e por isso não tem unhas tão bem cuidadas. Isso, contudo, só está vinculado aos dias da semana, que são os dias dedicados ao trabalho mais árduo. Para ocasiões festivas e mesmo para ir à missa, as mulheres mantêm cuidados com a aparência que nada diferem das que não trabalham em atividades do meio rural.

A religião configura-se, dessa forma, numa importante aliada ao processo de homogeneização das comunidades de descendentes de imigrantes europeus. É considerada ainda um atributo diferenciador entre os moradores de localidades como a Linha Acre, os quais (em especial os idosos) conferem maior distinção às pessoas que participam das celebrações religiosas.

Conforme o entrevistado Tradicional/Orgânico 3, "quem não ia na igreja era praticamente excluído da sociedade. Se dizia que era uma pessoa fria, que não tem sentimento". E diz ainda que essa visão pejorativa repercutia de outras formas, até mesmo

\footnotetext{
Conforme Castro e Coelho (2013, p. 2), Pelznickel, que significa "Nicolau Peludo", é uma personagem que aparece anualmente durante as festividades de Natal e "cobra o bom comportamento das crianças, presenteando ou ameaçando de levar para o mato aquelas que desrespeitam os pais e não se comportaram de maneira adequada". Os autores reiteram que até a década de 80 tratava-se de uma personagem punitiva, que "invadia as casas - com o consentimento dos pais - e surrava aqueles que foram mal-comportados, nem que para isto os puxasse de baixo da cama. O abandono das práticas de castigo físico no ritual do Pelznickel coincide com o período em que foram tomadas iniciativas visando a coibir a agressão física às crianças, mais notadamente com o advento do Estatuto da Criança e do Adolescente (ECA) de 1990".
} 
nas relações de trabalho. Uma pessoa que não frequentava as celebrações religiosas era vista com certa desconfiança. Diante do que foi exposto, pode-se concluir que um território formado por imigrantes alemães e mantido ao longo do tempo por descendentes desses imigrantes mantém traços marcados por tais peculiaridades.

Este papel domesticador da religião foi percebido nos relatos dos entrevistados, que ao voltarem aos lugares da memória relacionados à infância, relataram fatos relacionados à violência que as crianças sofriam pelos professores, os quais eram escolhidos pelo vigário e mantidos pela comunidade.

Em comunidades rurais formadas por imigrantes europeus o professor assumia vários papéis dentro da comunidade. Era a figura representativa da família e da Igreja e, portanto, da preservação dos valores morais e éticos associados à manutenção da Kultur alemã, que está conectada à filosofia do Deutschtum. Essa relação amalgamada entre igreja, escola e comunidade também pôde ser constatada nos relatos dos entrevistados.

Conforme a depoente Tradicional/Orgânico 5, "quando a comunidade precisava de um professor ia perguntar pro padre vigário quem podia pegar pra professor, ele (o padre) que decidia isso, mas nós da comunidade que pagávamos os professores". Essa era, conforme explicado por Kreutz (1991), uma prática comum em comunidades formadas por imigrantes europeus:

Na colonização alemã também houve uma íntima conexão entre Igreja e escola. A vida em comum destes núcleos populacionais, a partir de uma base comum de produção, girava fundamentalmente em torno da Igreja e da escola. Esta interação fez com que ao passar dos anos se diferenciasse a figura do professor de acordo com sua orientação religiosa, católica ou evangélica, pois diversas eram as atribuições a ele confiadas numa ou em outra orientação religiosa. Assim, nas comunidades rurais católicas, o professor paroquial, além da função especificamente magisterial, também assumiu funções de coordenação e de serviços nas comunidades (KREUTZ, 1991, p. 58).

Em geral, os depoimentos relacionados à escola começaram com um tom de alegria, quando lembraram que tinham de caminhar por longos e difíceis trechos até que conseguissem chegar na escola, reminiscências que lhes alegravam o semblante, pois remetiam a tempos muito diferentes se comparados à atualidade. À medida, porém, que a memória foi sendo conduzida para o ambiente interno da sala de aula, começaram a vir lembranças da violência e do medo que sentiam. Todos lembraram de situações dessa natureza vividas direta ou indiretamente. Para fins de demonstração dessas lembranças, foram escolhidos dois depoimentos: o primeiro foi vivenciado pela entrevistada que viu a cena acontecer e guardou na mente a sensação do medo que sentiu por poder ocorrer algo parecido consigo e o segundo depoente vivenciou diretamente a violência e consegue lembrar disso ainda com detalhes.

Primeiro depoimento: violência vivida por ter assistido um colega ser agredido pelo professor:

Um dia um guri da aula trouxe um pedaço grande de cana-de-açúcar. Como ele queria mostrar para os outros, colocou perto do quadro negro. Tinha um aluno com dificuldade pra falar, ele gaguejava sempre, acho que era de medo. Sempre o professor chamava a gente pra ir na frente e ler um texto, aí quando chegou na vez 
desse aluno ler, ele fazia "hum" e não conseguia ler, ele não sabia. Aí o professor começou a bater nele com aquela cana-de-açúcar, até quebrar tudo, os pedaços voavam pra tudo que é lado e o guri já tava no chão e ele continuava a bater, batia até na cabeça dele, parecia que ele ia matar a criança ali. E nós tudo ficava apavorados, mas ninguém teve coragem de se levantar, porque se a gente apanhasse também, ainda ia apanhar de novo em casa do pai e da mãe (IDOSA 5-GRUPO 3)

Segundo depoimento: violência vivida diretamente. Nesse caso a agressora foi a esposa do professor.

Eu me lembro que eu tinha medo da mulher do professor que dava aula quando às vezes o professor precisava viajar. Porque ela era bruta com os alunos, gritava coisa e tal, então eu tinha um certo pavor dela. Daí um dia tinha que fazer uma conta no quadro-negro, quando ela me chamou pra fazer a conta me deu um branco né, daí ela me pegou na nuca e me bateu contra a parede porque eu não sabia fazer a conta. Outra coisa que eu lembro é que naquele tempo, por exemplo, se o professor se dava bem com esse vizinho, aquele ou aquele, então os filhos dele eram privilegiados contra os outros. E aqueles que eles tinham até por uma questão política porque o pai era de outro partido e aí os filhos dele eram mais perseguidos, mais judiados. Nós víamos o professor bater em crianças que elas chegavam a se mijar (TRADICIONAL/ORGÂNICO 3).

As "marcas" desse processo de homogeneização cultural por meio das práticas religiosas e da violência por parte dos professores também puderam ser constatadas na maneira como alguns entrevistados justificaram o fato de compreender, pelo menos em parte, por que as pessoas da comunidade participam menos das celebrações religiosas. Segundo eles, eram obrigados pelos pais a frequentar a missa e em casa tinham de participar de longas orações antes e depois das refeições. De acordo com o produtor Tradicional 4,

em casa, quando eu era criança, era sempre feita oração em alemão antes das refeições, isso era sagrado e às vezes rezava um terço. $E$ em algumas casas era rezado o terço ainda depois da janta antes de lavar a louça. E nos domingos tinha quer ir sempre na missa, chovendo, não chovendo, seja como for o tempo, era uma obrigação, como se diz, as pessoas levavam mais assim na obrigação e hoje em dia não.

Especificamente em relação a menor participação da comunidade nas atividades da igreja, o depoente produtor Tradicional/Orgânico 2 traduziu seu sentimento de forma bastante contundente, conforme transcrição do trecho gravado na entrevista:

Pergunta: A participação das pessoas nas atividades da igreja, você acha que está diminuindo? Resposta: Muito.

Pergunta: Por qual a razão que você considera isso? Resposta: Olha, por uma parte há o esvaziamento da comunidade, por outra parte o povo se tornou mais liberal, porque antigamente pra nós era dever. Quem não ia na missa estava fazendo um pecado né, e hoje não se tem mais esse conceito. Era mais impositivo nos tempos passados. 
Tanto nas narrativas anteriores como nos demais aspectos apresentados ao longo do texto, é possível perceber a existência de certos pontos de ruptura com os elementos relacionados a valores passados entres as gerações, mas em especial o que se nota são cristalizações que se observam em posturas que procuram manter hábitos e costumes presentes em sua cotidianidade.

Com base nos pressupostos da memória cultural compreende-se que ações pautadas na visualização de protagonismo de grupos sociais em localidades como a comunidade rural de Linha Acre devam considerar sua memória, devido à capacidade que esta possui em se fazer presente no cotidiano destas famílias e na comunidade como um todo. O desafio que se lança, contudo, é abrir-se para possibilidades que procurem identificar necessárias rupturas com construções estereotipadas repassadas entre as gerações e que possam representar entraves ao desenvolvimento de comunidades como a que foi estudada.

\section{CONSIDERAÇÕES FINAIS}

A partir dos elementos apresentados e discutidos ao longo deste artigo, pode-se afirmar que no caso da comunidade rural pesquisada os estereótipos linguagem, trabaIho e religião configuram-se como verdadeiras "marcas" no território, materializando-se como fatores enraizados na cotidianidade destes grupos sociais por meio de tradições, hábitos e costumes. Sendo a memória a porta reveladora destes aspectos, pode-se depreender que estes sejam importantes aliados para a construção de alternativas para o meio rural, uma vez que estão intrinsecamente relacionados às características mais profundas desses indivíduos e na comunidade e podem, portanto, contribuir para a visualização de novos usos deste território.

Importante ressaltar, entretanto, que os novos usos do território estejam pautados em dois eixos centrais: o primeiro a valorização da historicidade dos atores sociais que fazem parte da comunidade, a fim de que estes possam reconhecer sua identidade em ações que visem a alcançar novos significados à localidade a que pertencem. Nesse sentido, compreende-se que o segundo eixo deva ser o engajamento de diferentes atores neste processo, tais como as cooperativas e entidades que representam os produtores rurais. Tal afirmativa sustenta-se na ideia de que construções do tipo down-up devam ser estruturadas e organizadas de forma que realmente façam sentido aos moradores e que paulatinamente estes se sintam capazes de desenvolver sua autonomia ao abrir-se novos ângulos de percepção sobre si mesmos e seu entorno.

As reflexões apresentadas ao longo do texto, contudo, conduzem a uma consideração adicional: Será que o espelho das tradições, dos hábitos e dos costumes reflete a realidade? Ou será que sua imagem foi construída por bases distorcidas? Importantes indagações que devem ser consideradas, uma vez que as construções estabelecidas no passado podem ter se dado a partir de condições que desconsideraram elementos que não se vinculavam ao que era aceito como relevante por grupos detentores de poder, como em comunidades formadas por teuto-brasileiros com os esforços empreendidos para a manutenção do Deutschtum. E, além disso, podem ter sido construídas sem levar em conta peculiaridades de histórias de vida que só poderiam ter sido consideradas se 
tivessem sido estabelecidas relações com vínculos com maior profundidade de compreensão do ser humano, o que só seria possível com a presença de espíritos livres e descomprometidos com o passado.

Há de se considerar, portanto, que a veneração às tradições, aos hábitos e aos costumes pode representar um entrave à aceitação de novas formas de perceber a vida. Preconceitos e estereótipos cristalizados no passado perpetuam-se entre as gerações, paralisando as forças que apontam para novos horizontes. É neste ponto que se faz necessário chamar a atenção ao risco relacionado à homogeneização cultural, assinalando que projetos que objetivem o desenvolvimento rural introduzam atividades que promovam a constante troca de experiências com outras culturas, valorizando a diversidade como uma alternativa ao bloqueio à heterogeneidade cultural sofrido ao longo do tempo desde a ocupação de comunidades formadas por grupos de descendentes de imigrantes alemães, como a que foi estudada.

Reflexões que se tornam atuais e pertinentes ao adentrar-se em espaços como a comunidade rural de Linha Acre, onde se faz urgente a busca por alterativas que visem a sua continuidade. Para que haja verdadeiro protagonismo destes grupos sociais na construção de alternativas do tipo down-up, contudo, reitera-se a importância de se ater aos aspectos relacionados a memória para o reconhecimento de especificidades que possam olhar de forma mais crítica o passado e construir as bases para um futuro livre das amarras impostas por grupos detentores de poder.

\section{REFERÊNCIAS}

BOSI, Ecléa. Memória e sociedade - lembranças de velhos. 2. ed. São Paulo: T.A. Queiroz Editor, 1983.

BOSI, Ecléa. O tempo vivo da memória: ensaios de psicologia social. 3. ed. São Paulo: Ateliê Editorial, 2013.

BRASIL. Decreto-Lei n. 406, 4 de maio de 1938. Dispõe sobre a entrada, de estrangeiros no território nacional [revogada pela Lei 6815 - 19/08/1980]. Disponível em: https://www.planalto.gov.br/ccivil_03/ decreto-lei/1937-1946/del0406.htm. Acesso em: 15 jul. 2015.

CASTRO, Álisson Sousa; COELHO, Ilanil. A importância do corpo nos processos rituais de um patrimônio cultural imaterial. 2013. Disponível em: http://www.anpuh-sc.org.br/spcsc\%202013\%20textos\%20pdf/ spcsc2013_acastro_a\%20importancia\%20do\%20corpo.pdf. Acesso em: 10 out. 2017.

ELIAS, Norbert. O processo civilizador: uma história dos costumes. Rio de Janeiro: Jorge Zahar Ed., 1990. Vol. 1.

KREUTZ, Lúcio. O professor paroquial: magistério e imigração alemã. Porto Alegre: Ed. da UFRGS; Florianópolis: Ed. da UFSC; Caxias do Sul: Educs, 1991.

MINAYO, Maria Cecília de Souza. Pesquisa social: teoria, método e criatividade. Petrópolis: Editora Vozes Limitada, 2016.

NIETZSCHE, F. Genealogia da moral: uma polêmica. Trad. Paulo César de Souza. São Paulo: Companhia das Letras, 2009.

NIETZSCHE, F. A gaia ciência. São Paulo: Companhia das letras, 2001.

NUNES, Fernanda da Rocha Marques. Os paradoxos da memória nos textos de Walter Benjamin sobre a infância e a juventude. 2014. 98f. Dissertação de Mestrado (Programa de Pós-Graduação em Memória Social) - Universidade Federal do Estado do Rio de Janeiro, Rio de Janeiro, 2014.

PUPP SPINASSÉ, Karen. Os imigrantes alemães e seus descendentes no Brasil: a língua como fator identitário e inclusivo. Conexão Letras, Porto Alegre, vol. 3, n. 3, p. 125-140, 2008.

SALLES, Iraci Galvão. Trabalho, progresso e a sociedade civilizada. São Paulo: Hucitec; Pró-Memória Instituto Nacional do Livro, 1986.

SEVERINO, Antônio Joaquim. Metodologia do trabalho científico. 23. ed. São Paulo: Cortez, 2007.

SEYFERTH, Giralda. A idéia de cultura teuto-brasileira: literatura, identidade e os significados da etnicidade. Horizontes Antropológicos, v. 10, n. 22, p. 149-197, 2004. 
SEYFERTH, Giralda. A representação do "trabalho alemão" na ideologia étnica teutobrasileira. Boletim do Museu Nacional - Antropologia, n. 37, p. 1-33, 1982.

SILVA, Nelson José Batista da. Memória, esquecimento e criação em Nietzsche. 2012, 90f. Dissertação (Programa de Pós-Graduação em Memória Social) - Universidade Federal do Estado do Rio de Janeiro, Rio de Janeiro, 2012.

THEIS, Wolfgang. Heimat-um termo abstrato. Revista Primus Vitam, v. 4, p. 1-7, 2012.

TORNQUIST, Ingrid Margareta. “Das Hon Ich von Meiner Mama” Zu Sprache Und Ethischen Konzepten Unter Deutschstämmigen in Rio Grande do Sul. Uppsala: Umeå, 1997.

WERLE, André Carlos. Jesuítas alemães e o projeto de uma colônia étnica e religiosamente homogênea no Extremo Oeste Catarinense: Porto Novo (Itapiranga). Revista Cadernos do Ceom, v. 16, n. 15, p. 221258, 2014.

WOODWARD, Kathryn. Identidade e diferença: uma introdução teórica e conceitual. In: Identidade e diferença: a perspectiva dos estudos culturais. Petrópolis: Vozes, 2014. p. 7-72. 